TAO, Vol. 13, No. 3, 299-312, September 2002

\title{
Estimates of Source Parameters of Two Large Aftershocks of the 1999 Chi-Chi, Taiwan, Earthquake in the Chia-Yi Area
}

\author{
Ming-Wey Huang ${ }^{1, *}$, Jeen-Hwa Wang ${ }^{1}$, Ruey-Der Hwang ${ }^{2}$, and Kou-Cheng Chen ${ }^{1}$
}

(Manuscript received 8 April 2002, in final form 8 July 2002)

\begin{abstract}
Two large aftershocks of the 1999 Chi-Chi earthquake $\left(M_{L}=6.4\right.$ and 6) occurred to the south of the Chelungpu fault and in the Chia-Yi in Taiwan. Near-field seismograms estimated some source parameters of the two events. The near-field displacement spectra can be described by Brune's $\omega$-square model. The estimated values of stress drop $(\Delta \sigma)$, apparent stress $\left(\sigma_{a}\right)$, and scaled energy $\left(E_{s} / M_{0}\right)$, of these two events varied from station to station with mean values of: $\Delta \sigma=991$ bars, $\sigma_{a}=402$ bars, and $E_{s} / M_{0}=1.3 \times 10^{-3}$ for the $M_{L} 6.4$ event; and $\Delta \sigma=831$ bars, $\sigma_{a}=337$ bars, and $E_{s} / M_{0}=1.0 \times 10^{-3}$ for the $M_{L} 6.0$ one. This shows a high dynamic stress drop between these two events. The larger values calculated from the $M_{L} 6.4$ event indicated a higher percentage transformation of strain energy into seismic-wave energy comparing to the $M_{L} 6.0$ event.
\end{abstract}

(Key words: Displacement spectra, Stress drop, Apparent stress, Scaled energy)

\section{INTRODUCTION}

Stress change on the fault plane is one of the significant indicators specifying dynamic behavior of earthquake ruptures (e.g., Brune 1970). The scaled energy $\left(\mathrm{E}_{\mathrm{s}} / \mathrm{M}_{\mathrm{o}}\right)$ defines the ratio of seismic-wave energy $\left(E_{s}\right)$, over seismic moment $\left(M_{o}\right)$, is related to the degree of friction drop and can indicate the stress condition of an earthquake (Kikuchi and Fukao 1988; Kanamori and Heaton 2000). However, the values of $E_{s} / M_{o}$ estimated from far-field seismograms generally show high divergence (Vassiliou and Kanamori 1982; Kikuchi and Fukao 1988; Choy and Boatwright 1995) due to the uncertainties of seismic-wave energy estimation, the seismic-wave energy calculated from near-field data is generally larger than that estimated from far-field ones (Smith et al. 1991; Singh and Ordaz 1994; Hwang et al. 2001). This might be due to existence of more high-frequency signals in near-field seismograms than in far-field ones. In addition, the ratio of apparent stress $\left(\sigma_{\mathrm{a}}\right)$, to static stress drop $(\Delta \sigma)$, is also used to

\footnotetext{
${ }^{1}$ Institute of Earth Sciences, Academia Sinica, Nankang, Taipei, Taiwan

${ }^{2}$ Center of General Education, Hsing-Kou University, Tainan, Taiwan

* Corresponding author address: Mr. Ming-Wey Huang, Institute of Earth Sciences, Academia Sinica, P.O. Box 1-55, Nankang, Taipei, Taiwan, ROC; E-mail: mwhuang@earth.sinica.edu.tw
} 
account for the relationship of dynamic stress and final stress during earthquake rupturing processes (Kikuchi and Fukao 1988; Smith et al. 1991; Ramón Zúñiga 1993; Kanamori 1994; Hwang et al. 2001). A stress model specified with frictional overshoot, as the final stress level being lower than the dynamic one (see Kikuchi and Fukao 1988), further confirms Vassiliou and Kanamori's earlier observations (1982). In contrast, Ramón Zúñiga (1993) considered another model of partial-stress-drop model to interpret the observations by Smith et al. (1991) and some others. The distinction of these two models might be due to the differences seismicwave energy estimation. Choy and Boatwright (1995) improved the estimates of seismic-wave energy from teleseismic data, and stated the frictional overshoot model is more appropriate than the partial-stress-drop model. Hwang et al. (2001) also obtained the same conclusion for the 1999 Chi-Chi earthquake.

On September 20th, 1999, rupturing along the Chelungpu fault initiated an $\mathrm{M}_{\mathrm{s}} 7.6$ earthquake beneath the town of Chi-Chi in central Taiwan (cf. Ma et al. 1999; Shin et al. 2000; Wang et al. 2000). Huang et al. (2001) and Hwang et al. (2001) estimated the stress drop, apparent stress, and $\mathrm{E}_{\mathrm{s}} / \mathrm{M}_{\mathrm{o}}$ of the earthquake from near-field seismograms through different ways. Their results showed that the stress drop is higher in the north segment of the fault than the south one. About one month after the miainshock, two large aftershocks of $M_{L}=6.4$ and $\mathrm{M}_{\mathrm{L}}=6.0$ ) are $5 \mathrm{~km}$ apart from each other, and located near the south end of the fault in the ChiaYi area. The epicenters of the two events are shown in Fig. 1. This paper estimates the stress drop of these two events their relationship with the mainshock.

Since 1991, the Central Weather Bureau (CWB) has constructed an island-wide network composed of more than 600 free-field strong-motion stations. This network recorded a huge number of high-quality data generated by the Chi-Chi earthquake and its aftershocks (cf. Shin et al. 2000). Several stations in the vicinity of epicenters recorded and generated seismograms of two aftershocks (Fig. 1). Such near-field seismograms can be used to estimate the stress drop, apparent stress, and $\mathrm{E}_{\mathrm{s}} \mathrm{M}_{\mathrm{o}}$ of these two aftershocks through a simple method proposed by Andrews (1986).

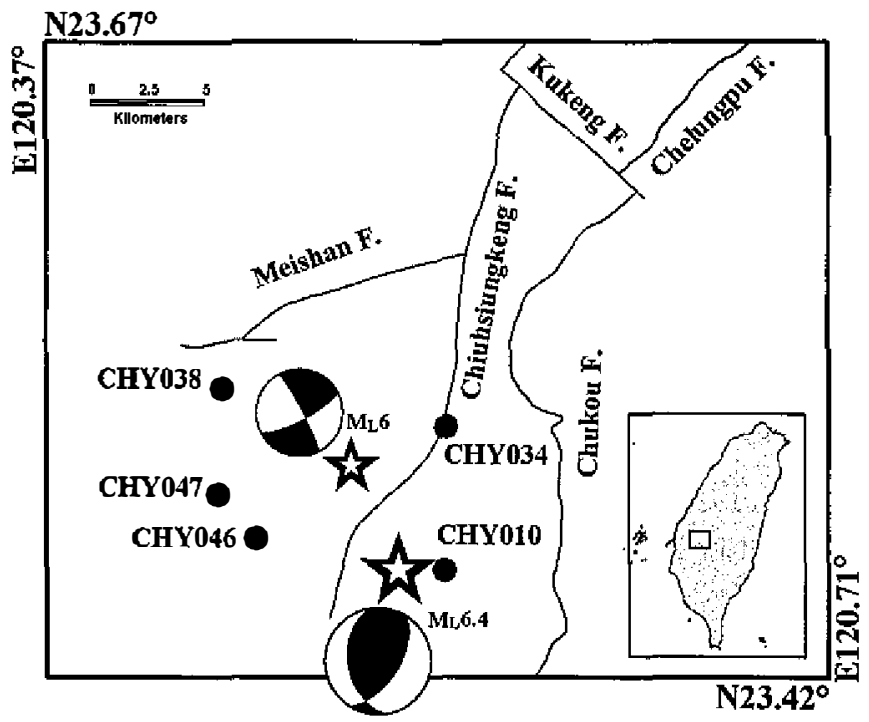

Fig. 1. The distribution of epicenters (denoted by a solid star) with focal mechanisms of the two aftershocks and the locations (shown by a solid circle) of five stations in use. 


\section{DATA}

The accelerographs, operated by the CWB, are specified by a flat frequency response from $\mathrm{DC}$ to about $50 \mathrm{~Hz}$ with 16-bit resolution for full scale digital recordings up to $2 \mathrm{~g}$. The accelerogram is recording at a rate of 200 samples per second for A900 type, and 250 samples per second for IDS type (Liu et al. 1999). On October 22nd, 1999, two large aftershocks with local magnitudes of 6.4 and 6.0, respectively, were located near the southern end of the Chelungpu fault in the Chia-Yi area. Although the CWB routinely determine the hypocenters of these two aftershocks. In order to obtain more reliable hypocenters for the source parameter estimations, we relocated epicenters at $23.47^{\circ} \mathrm{N}, 120.52^{\circ} \mathrm{E}$ with a focal depth of $24.5 \mathrm{~km}$ for the $\mathrm{M}_{\mathrm{L}} 6.4$ event, and at $23.51^{\circ} \mathrm{N}, 120.50^{\circ} \mathrm{E}$ with a focal depth of $24.0 \mathrm{~km}$ for the $\mathrm{M}_{\mathrm{L}} 6.0$ one. The focal mechanisms of these two events show thrust faulting for the $M_{L} 6.4$ event and strikeslip faulting for the $M_{1} 6$ one (Kao and Angelier 2001; Fig. 1). The Harvard CMT earthquake catalogue shows $M_{o}=6.9 \times 10^{24}$ dyne-cm with $M_{s}=5.6$ for the $M_{L} 6.4$ event and $M_{o}=2.5 \times 10^{24}$ dyne-cm with $M_{s}=5.3$ for the $M_{L} 6.0$ one. Many seismic stations recorded these two events, and generated several seismograms. In order to reduce the path effects, we only used the seismograms recorded from five near-field stations CHY046, CHY038, CHY047, CHY010, and CHY034 (shown by solid circles in Fig. 1) with their distance to epicenter ranging from $2 \mathrm{~km}$ to $11 \mathrm{~km}$.

Owing to the flat and wide frequency response of the instruments, the instrumental effect on the accelerograms can be ignored since only the transverse-component waveforms are used to estimate the values of $\sigma_{\mathrm{a}}$ and $\Delta \sigma$. We rotated the waveforms from the original geographic coordinate system to a system defined based on the wave propagating direction. This new system contains 3 directional components of $R, N$ and $T$. The radial $(R)$ component defines the vibrating motion along the hypocenter-station while the $\mathrm{N}$-component is on the slant plane and the T-component is normal to the slant plane. Both $\mathrm{T}$ and $\mathrm{N}$ components are normal to the $\mathrm{R}$ component. We further add the waveforms of $\mathrm{T}$ and $\mathrm{N}$ components to form a composite waveform. The velocity and displacement waveforms are integrated once and twice, respectively, from the accelerograms. Figure 2 shows the rotated accelerograms, velocity waveforms, and displacement waveforms for the $\mathrm{M}_{\mathrm{L}} 6.4$ event with the left-handed-side diagrams for the $\mathrm{T}$-component and the right-handed-side ones for the $\mathrm{N}$-component. Figure 3 shows the similar waveforms for the $M_{L} 6.0$ event. The two vertical dashed lines marked the existence boundaries of predominant signal in Figs. 2 and 3. These signal are used for the source parameters estimations below. Obviously, the waveform of the predominant signal is less complicated for the $M_{L} 6.4$ event than for the $M_{L} 6.0$ one, but with similar duration of 3 seconds at all stations for the two events.

\section{METHOD}

This study applied an objective method proposed by Andrews (1986) for estimating the values of stress drop and apparent stress of the two aftershocks. Based on this method, the integrals of squared velocities and squared displacements are first applied to measure seismicwave energy $\left(E_{s}\right)$ and seismic moment $\left(M_{o}\right)$, respectively, of an earthquake by means of the 
T-comp.
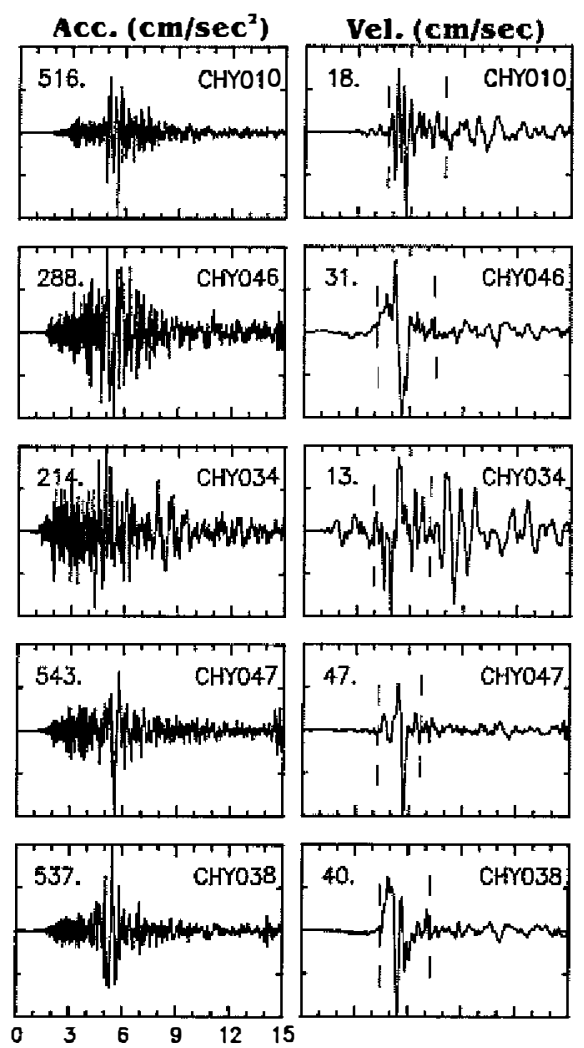

Time (sec)
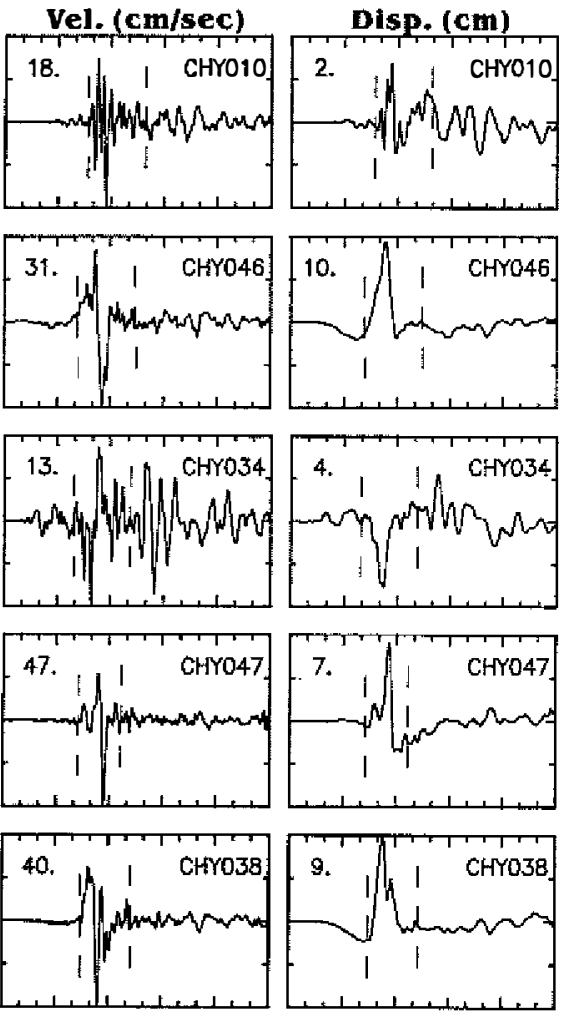

N-comp.
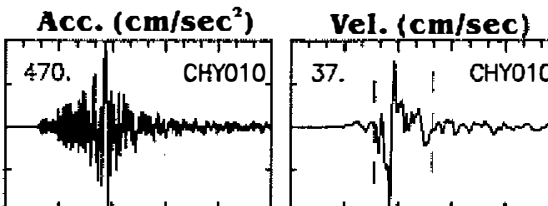

Disp. (cm)
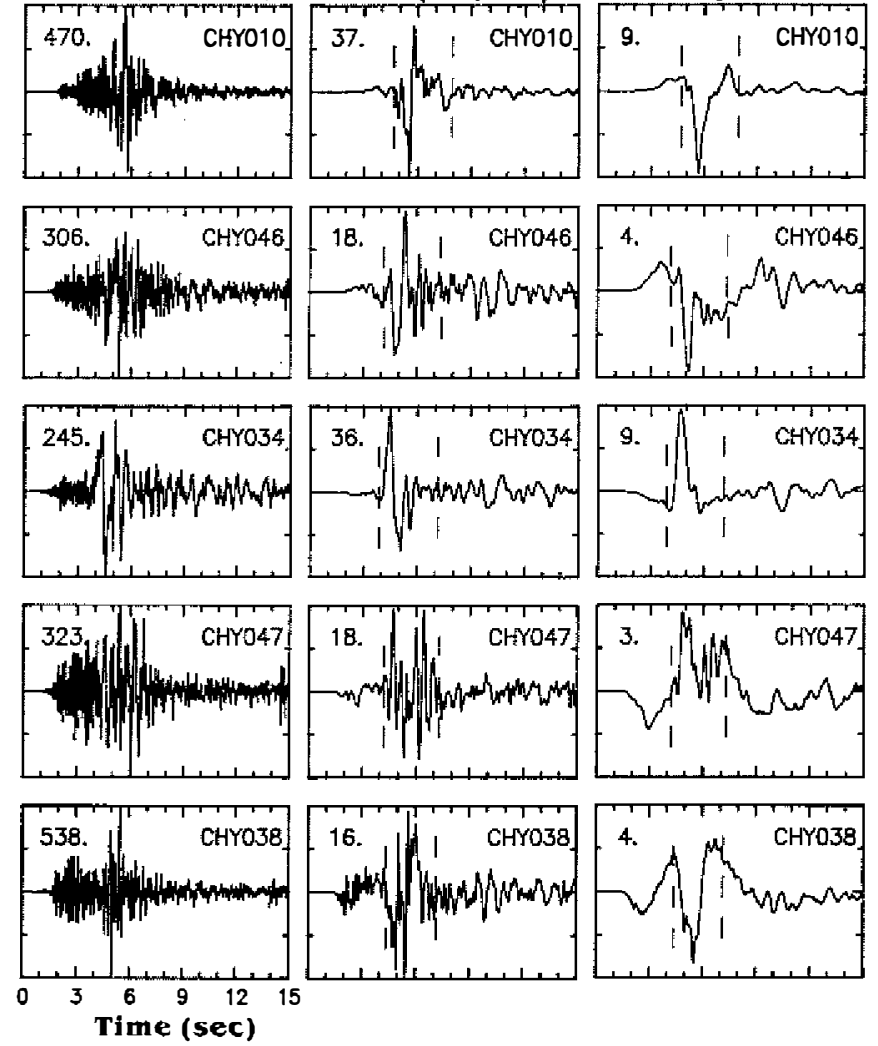

Fig. 2. The diagrams showing $\mathrm{T}$ - and $\mathrm{N}$-component velocity and displacement seismograms of the $\mathrm{M}_{\mathrm{L}} 6.4$ aftershock from five stations integrated once and twice from the original accelerograms after a band-pass filter with frequencies ranging from 0.06 to $6 \mathrm{~Hz}$. The dashed lines specify the part of seismogram used for the source parameter estimations. 
T-comp.
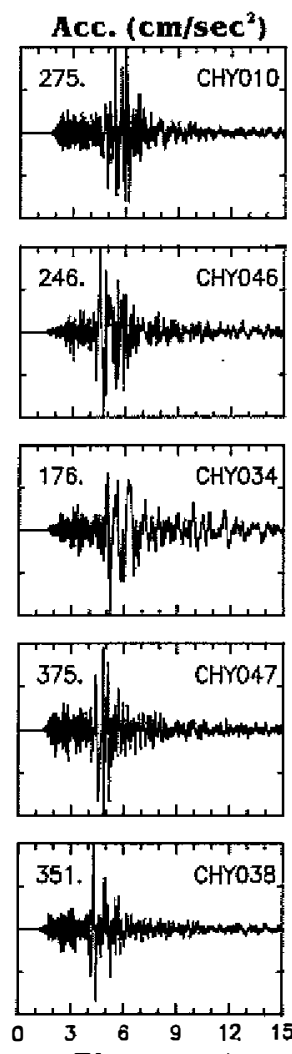

Time (sec)
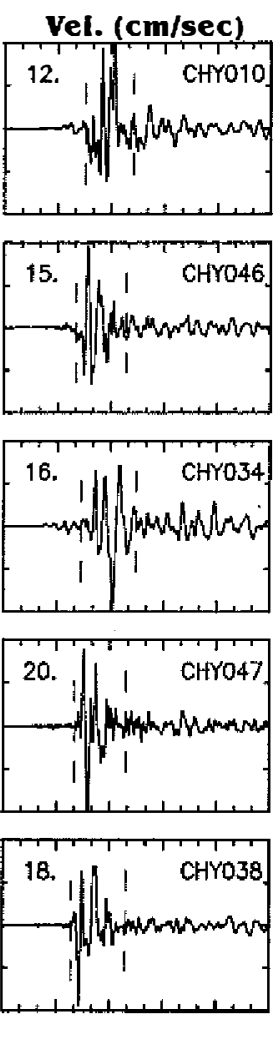

HYo38

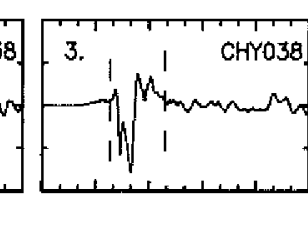

Disp. (cm)
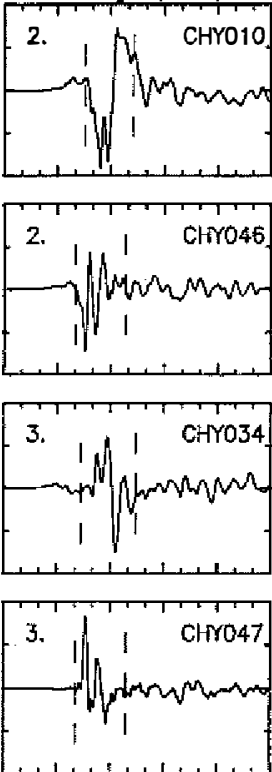

N-comp.

Acc. $\left(\mathrm{cm} / \mathrm{sec}^{2}\right)$
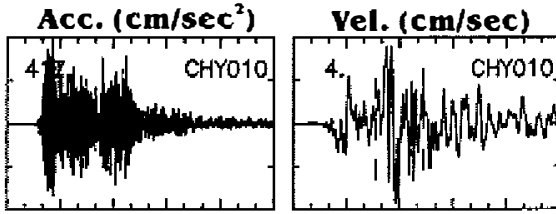

Disp. $(\mathbf{c m})$
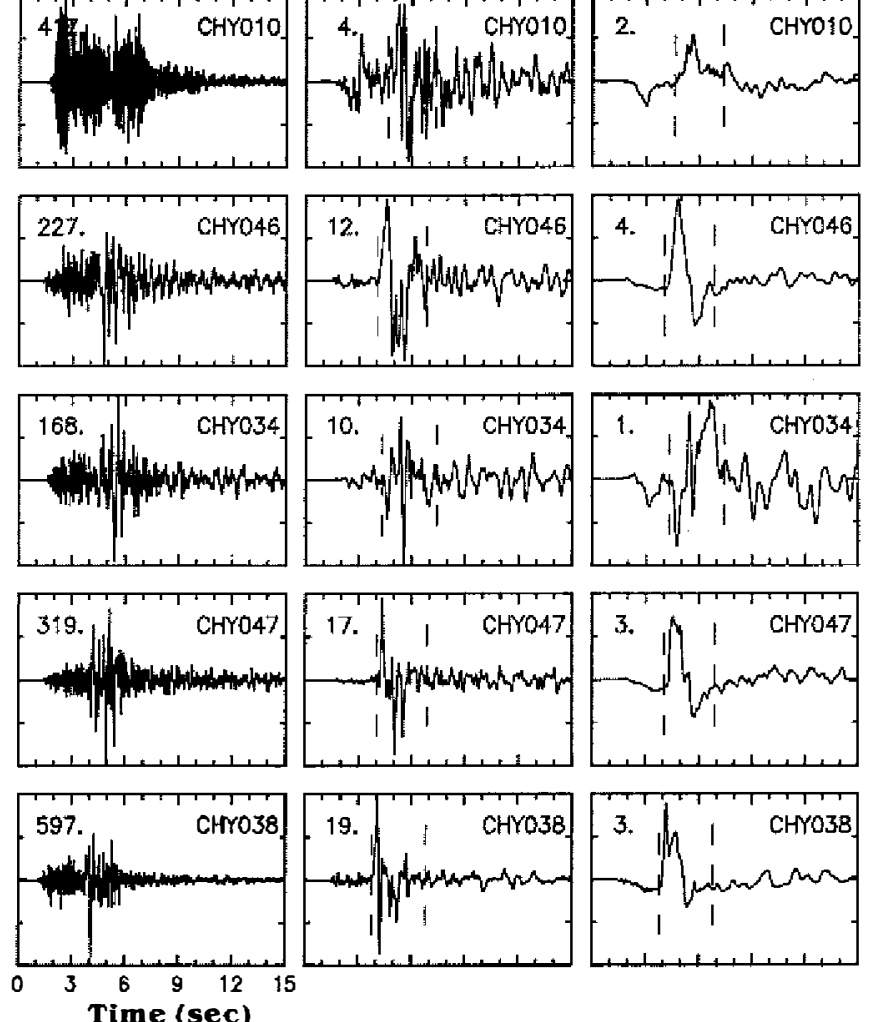

Fig. 3. The diagrams showing $\mathrm{T}$ - and $\mathrm{N}$-component velocity and displacement seismograms of the $\mathrm{M}_{\mathrm{L}} 6.0$ aftershock from five stations integrated once and twice from the original accelerograms used after a band-pass filter with frequencies ranging from 0.06 to $6 \mathrm{~Hz}$. The dashed lines specify the part of seismogram used for source parameter estimations. 
following equation:

$$
E_{s}=S_{a} \rho \beta I_{y},
$$

and

$$
M_{o}=4 \pi R \rho \beta^{3} \Omega_{o} .
$$

$S_{s}=2 \pi R^{2}$ is the surface area of a hemisphere with a radius $R$ based on the assumption that the spherical spreading is confined to the lower hemi-sphere of the source area (Bolt 1986). $R$ is the distance from the source to the station, and $\Omega_{\mathrm{o}}=2 \mathrm{I}_{\mathrm{v}}{ }_{\mathrm{v}}^{-1 / 4} \mathrm{I}_{\mathrm{D}}{ }^{3 / 4}$ (Andrews 1986), where $\mathrm{I}_{\mathrm{v}}$ and $\mathrm{I}_{\mathrm{D}}$ are, respectively, the squared-velocity and squared-displacement integrals in time domain at the low-frequency spectrum level according to Brune's $\omega$-squared model (Brune 1970). Although the corner frequency, $f_{c}$, can be calculated from $\left(I_{v} / I_{D}\right)^{1 / 2} / 2 \pi$ (Andrews, 1986), the $f_{c}$ values are $0.8 \mathrm{~Hz}$ for $M_{L} 6.4$ event and $1.2 \mathrm{~Hz}$ for the $M_{L} 6$ event as mentioned above (Fig. 4). The two qualities $\rho$ and $\beta$ denotes, respectively, the density and the $S$-wave velocity of the materials in the source area. In this study, we applied the same values of $\rho\left(2.4 \mathrm{~g} / \mathrm{cm}^{3}\right)$ and $\beta$ $(3.0 \mathrm{~cm} / \mathrm{sec})$ as the CWB for the routine earthquake location. In order to include the free surface amplification, the seismograms are corrected by a factor of 2 . Due to uneven distribution of stations, an average radiation pattem 0.66 for the dip-slip mechanism and 0.55 for the strikeslip mechanism for the $S$ waves are adopted to adjust the amount of seismic energy caused by a non-uniform spatial distribution of seismic-wave radiation patten (cf. Boore and Boatwright 1984).

According to Eqs. (1) and (2), Wyss and Brune (1968) defined the apparent stress $\left(\sigma_{\mathrm{a}}\right)$, as the product of the seismic efficiency and the averaged stress (neither of them can be determined seismologically directly.), in terms of

$$
\sigma_{a}=\mu \frac{E_{s}}{M_{o}},
$$

where $\mu$ is the rigidity of the materials in the source area. A commonly-used value of $\mu$ for the crust materials is $3.0 \times 10^{11}$ dyne- $\mathrm{cm}^{-2}$. The apparent stress is usually regarded as the product of seismic efficiency and averaged stress on the fault plane. From Brune's circular source model (1970), the static stress drop $(\Delta \sigma)$, is given in terms of the integrals of squared velocities and squared displacements as

$$
\Delta \sigma=\frac{2 R \rho}{2.34} I_{V}^{5 / 4} I_{D}^{-3 / 4}
$$

Of course, the attenuation effect of seismic waves propagating in between the hypocenter and the stations must be taken into account to adjust the recorded waveforms. Generally, a frequency-dependent parameter $\left(Q_{s}\right)$ represents the attenuation effect on the $S$ waves, and the averaged value of $Q_{s}$ is about 250 in the study area (Rau et al. 1996).

\section{RESULTS}

In addition to the instrumental response and noise, the choice of frequency range or period range of a filter retrieving the filtrated waveforms from the original will also influence the 

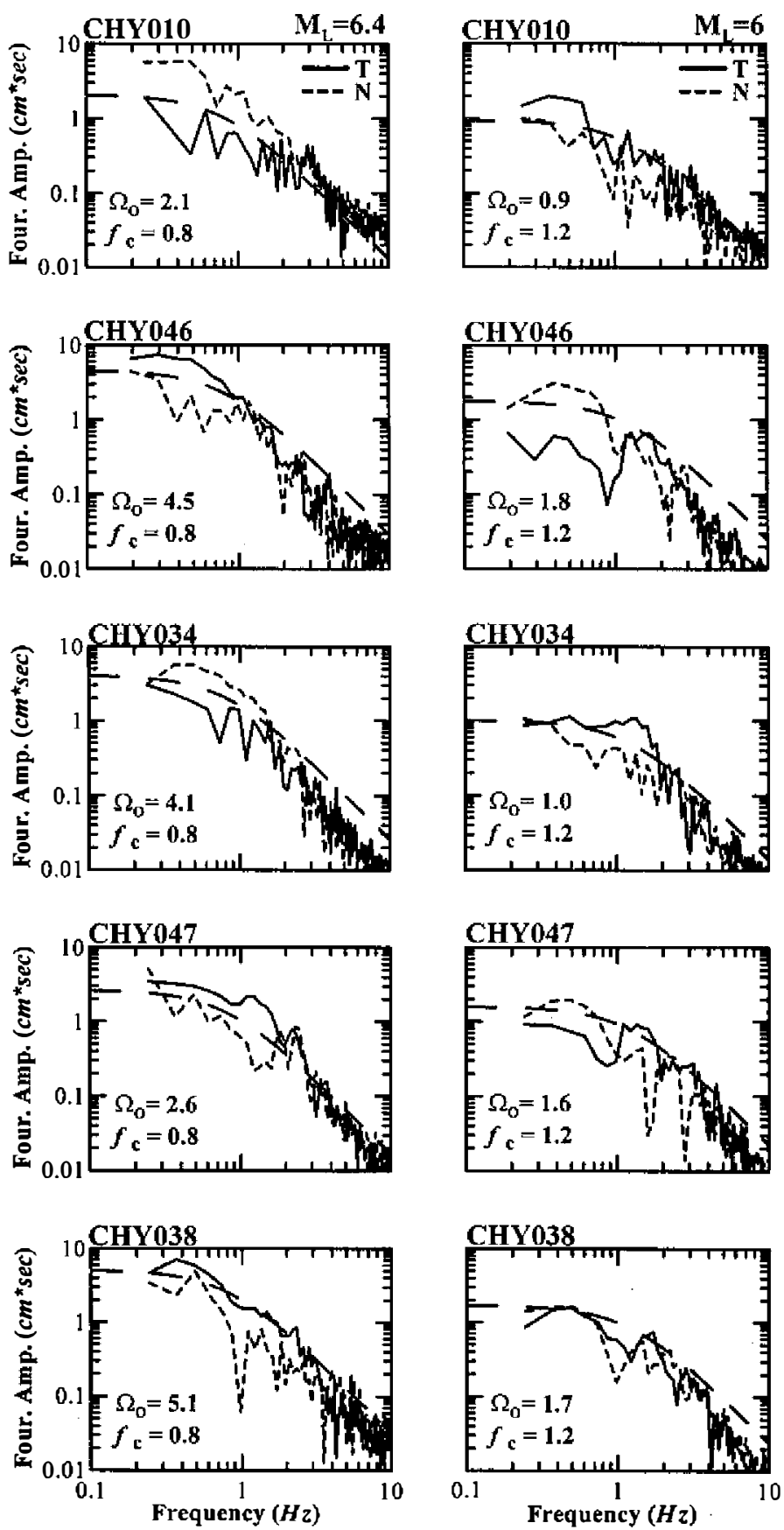

Fig. 4. Diagrams show the displacement spectra of T-component (in a dark solid line) and of $\mathrm{N}$-component (in a short-dashed solid line) and the theoretical spectrum (in a long-dashed line) calculated based on Brune's $\omega^{-2}$ model (Brune 1970). 
source parameters estimations. Hence, we first examine the effects on of a band-pass filter for source parameter estimations with different period ranges. Figure 4 shows the displacement spectra of the $\mathrm{T}$ - and $\mathrm{N}$-component waveforms at five stations by a solid line and short-dashed line respectively. In general, the spectral amplitudes of these two components are almost constant when $f$ is less than a certain frequency $\left(f_{c} ; f_{c}=0.8 \mathrm{~Hz}\right.$ for the $M_{L} 6.4$ event and $f_{c}=1.2 \mathrm{~Hz}$ for the $M_{L} 6.0$ one), and decrease with increasing frequency when $f>f_{c}$ (These as $f_{c}$ is named as corner frequency, cf. Aki 1967). The amplitudes of these two components are close to each other for all stations when $\mathrm{f}>\mathrm{f}_{\mathrm{c}}$, but different when $\mathrm{f}<\mathrm{f}_{\mathrm{c}^{\prime}}$. Moreover, the spectral amplitudes seem to decay with increasing frequency in a power-law function, with an exponent of about 2 when $f>f$. This indicates that the high-frequency spectral amplitudes can be described by the $\omega$-square scaling model (Aki 1967; Brune 1970). Hence, it is appropriate to use Andrews's method to estimate the low-frequency spectral level, i.e., $\Omega_{0}$, and related source parameters based on the $\omega$-squared model. The value of $\Omega_{0}$ for each station is the mean of two estimated values from the T- and N-component spectra. For the $\mathrm{M}_{\mathrm{L}} 6.4$ event, $\Omega_{\mathrm{o}}$ is $2.1 \mathrm{~cm}$-sec for CHY010, 4.5 cm-sec for CHY046, $4.1 \mathrm{~cm}$-sec for CHY034, $2.6 \mathrm{~cm}$-sec for CHY047, and 5.1 $\mathrm{cm}$-sec for CHY038. As for the $\mathrm{M}_{\mathrm{L}} 6.0$ event, $\Omega_{\mathrm{o}}$ is $0.9 \mathrm{~cm}-\mathrm{sec}$ for CHY010, $1.8 \mathrm{~cm}$-sec for CHY046, $1.0 \mathrm{~cm}$-sec for CHY034, $1.6 \mathrm{~cm}$-sec for CHY047, and $1.7 \mathrm{~cm}-\mathrm{sec}$ for CHY038. Figure 4 show the distribution of $\Omega_{\mathrm{o}}$ and $\mathrm{f}_{\mathrm{c}}$ values and the scaling law for each station determined from $\Omega_{\mathrm{o}}$ and $\mathrm{f}_{\mathrm{c}}$ values as long-dashed lines. The theoretical spectra amplitudes, except for CHY046 station, are indicated by long-dashed line in Fig. 4.

Figure 5 shows the variation between frequency with cumulative value of the sum of squared velocities of the $\mathrm{T}$ - and $\mathrm{N}$-component waveforms. The value defines kinematic energy by dividing seismic waves to the density of the material. The cumulative value increases rapidly within the range from $\mathrm{f}=0$ to $6 \mathrm{~Hz}$, and turns flat when $\mathrm{f}>6 \mathrm{~Hz}$. This means that seismicwave energy recorded at each station mainly distribute in the frequency range of 0 to $6 \mathrm{~Hz}$. Hence, $f=6 \mathrm{~Hz}$ is the upper bound frequency for waveform filtration. The variations for the five stations are different for these two events.

We retrieve the waveforms from rotated seismograms through a band-pass filter when different values of the upper bound period $\left(\mathrm{T}_{\text {upp }}\right)$ or the lower bound frequency $\left(\mathrm{f}_{\text {low }}\right)$ are taken. The lower bound period $\left(\mathrm{T}_{\text {low }}\right.$; associated with the upper bound frequency $\mathrm{f}_{\mathrm{upp}}$ ) of the filter is fixed at $0.17 \mathrm{sec}\left(\right.$ or $\mathrm{f}_{\text {upr }}=6 \mathrm{~Hz}$ ) for the two events. Figure 6 shows the distribution of $\sigma_{a}$ and $\Delta \sigma$ for each station with $T_{\text {upr }}$ between 2.5 and $17.5 \mathrm{sec}$. When the left-handed-side diagrams for the $M_{L} 6.4$ event and the right-handed-side ones for the $M_{L} 6.0$ event. The values of the two source parameters decreased rapidly with $\mathrm{T}_{\mathrm{upr}}$, and then approach individual constants when $\mathrm{T}_{\text {upr }}>10$ seconds. The distance varies from the two epicenters to five stations. Table 1 listed the averaged values of $\sigma_{\mathrm{a}}$ and $\Delta \sigma$ of $\mathrm{T}_{\text {upr }}$ from $10 \mathrm{sec}$ to $17.5 \mathrm{sec}$ obtained at the five stations of the two aftershocks are listed in Table 1 . The averaged values are: $\Delta \sigma=991$ bars and $\sigma_{\mathrm{a}}=402$ bars for the $M_{L} 6.4$ event, and $\Delta \sigma=831$ bars and $\sigma_{a}=337$ bars for the $M_{L} 6.0$ one. In order to examine the possible effect of distance variations, we plot the values of $\sigma_{\mathrm{a}}$ and $\Delta \sigma$ against distance for the two events (a solid circle for the $M_{L} 6.4$ event and an solid triangle for the $M_{L} 6$. 0 one) in Fig. $7 a$ along with the averaged values of these two events (a solid line for the $M_{L} 6$. 4 event and a dashed line for the $M_{L} 6.0$ one).

Unlike the values of $\Delta \sigma$ and $\sigma_{\mathrm{a}}$ the $\mathrm{E}_{\mathrm{s}}$ and $\mathrm{M}_{\mathrm{o}}$ values do not change too much from 


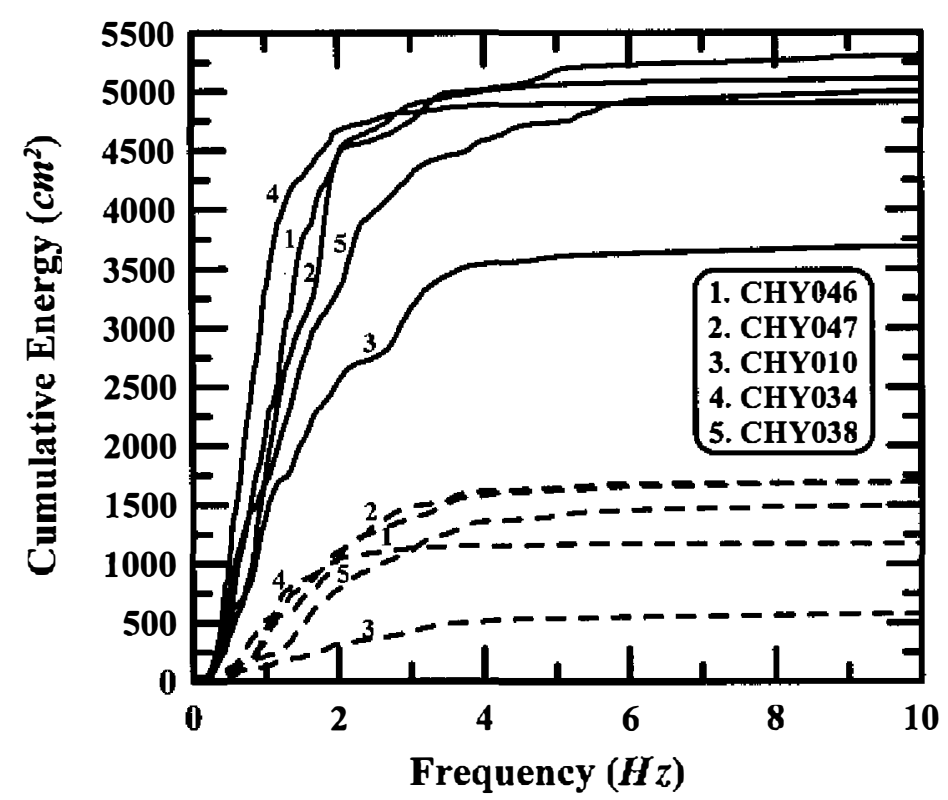

Fig. 5. Distribution of cumulative energy of the two components in use with frequency for the two aftershocks (solid lines for the $M_{L} 6.4$ aftershock and dashed lines for the $\mathrm{M}_{\mathrm{L}} 6.0$ one) recorded from the five stations ( 1 for CHY046, 2 for CHY047, 3 for CHY010, 4 for CHY034, and 5 for CHY038).

station to station (Fig. 7b). The Harvard CMT earthquake catalogue shows $\mathrm{M}_{0}=6.9 \times 10^{24}$ dyne$\mathrm{cm}$ with $M_{\mathrm{s}}=5.6$ for the $\mathrm{M}_{\mathrm{L}} 6.4$ event, and $\mathrm{M}_{\mathrm{o}}=2.5 \times 10^{24}$ dyne- $\mathrm{cm}$ with $\mathrm{M}_{\mathrm{s}}=5.3$ for the $\mathrm{M}_{\mathrm{L}} 6.0$ one. The estimating method for $\mathrm{E}_{\mathrm{s}}$ values developed by Choy and Boatwright (1995) yield $\mathrm{E}_{\mathrm{s}}=6.3 \times 10^{19} \mathrm{erg}$ and $2.2 \times 10^{19} \mathrm{erg}$, respectively, for the two events, thus leading to $E_{s} / M_{o}=9.1 \times 10^{-6}$ for the $M_{L} 6.4$ event and $E_{s} / M_{o}=8.8 \times 10^{-6}$ for the $M_{L} 6.0$ one. Figure $7 b$ also indicates $E_{s}$ and $M_{o}$ values as open circles for the $M_{L} 6.4$ event, open triangles for the $M_{L} 6.0$ one, and solid squares from near-field data by Hwang et al. (2001). Lines associated with four values of $E_{s} / M_{o}$, i.e., $5 \times 10^{-3}, 5 \times 10^{-4}, 5 \times 10^{-5}$, and $5 \times 10^{-6}$, calculated from the relation between $\mathrm{E}_{\mathrm{s}}$ and $\mathrm{M}_{\mathrm{o}}$ calculated by Vassiliou and Kanamori (1982) and Kikuchi and Fukao (1988) for global observations. Included in Table 1 are the averaged values of $E_{s}, M_{o}$, and $E_{s} / M_{o}$ of the five stations for the two events estimated from related data: $\mathrm{M}_{\mathrm{o}}=1.2 \times 10^{25}$ dyne-cm, $\mathrm{E}_{\mathrm{s}}=1$. $6 \times 10^{22} \mathrm{erg}$, and $\mathrm{E}_{\mathrm{s}} \mathrm{M}_{\mathrm{o}}=1.3 \times 10^{-3}$ for the $\mathrm{M}_{\mathrm{L}} 6.4$ event; and $\mathrm{M}_{\mathrm{o}}=4.6 \times 10^{24}$ dyne-cm, $\mathrm{E}_{\mathrm{s}}=4.8 \times 10^{21}$ erg, and $E_{s} / M_{o}=1.0 \times 10^{-3}$ for the $M_{L} 6.0$ one. It is obvious that the estimated the source parameters are bigger for the larger aftershock than the smaller one.

\section{DISCUSSION}

Figure 4 shows the displacement spectra for the five stations ( solid line for the T-component and short-dashed one for the $\mathrm{N}$-component). It is obvious that all spectral amplitudes 

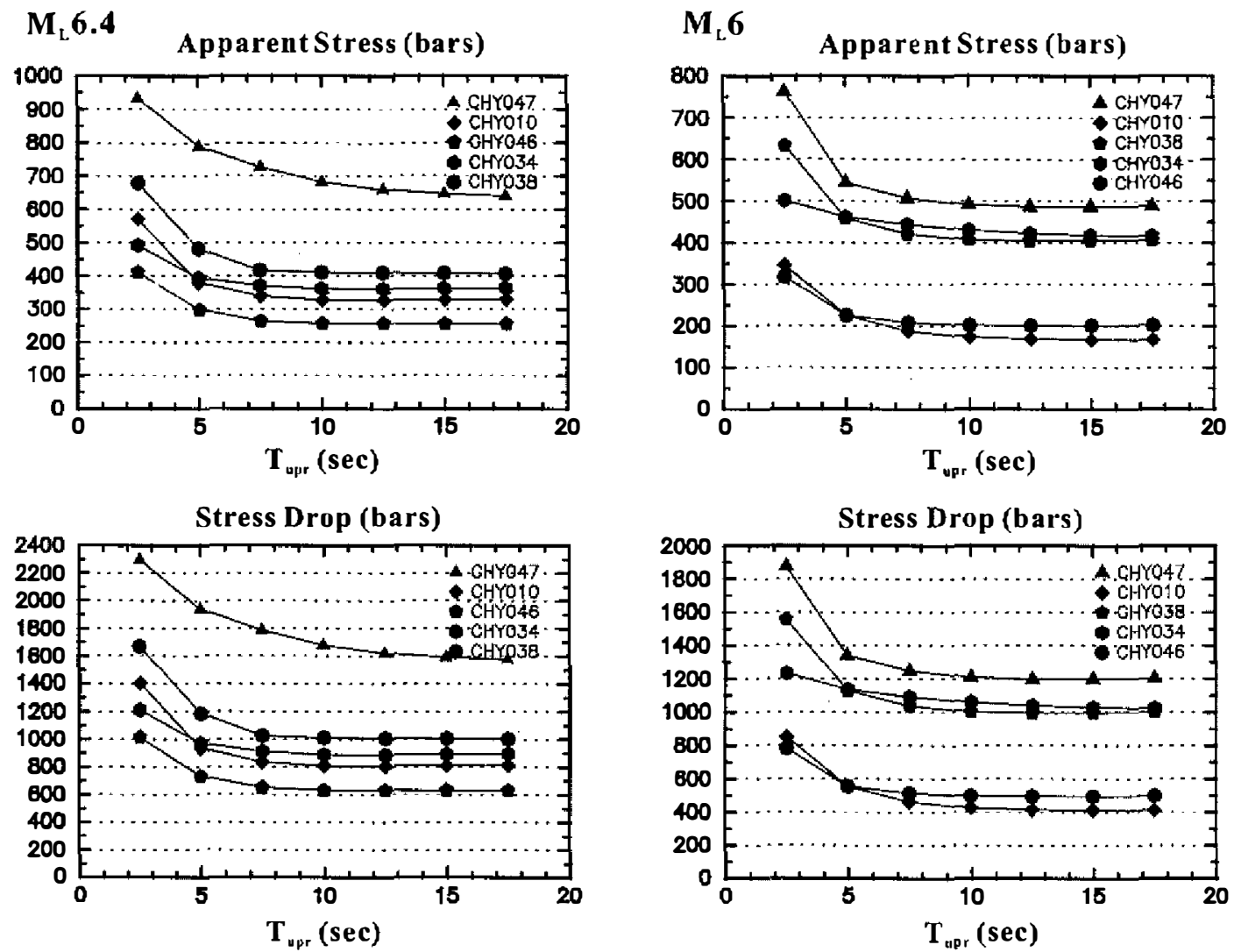

Fig. 6. Distribution of apparent stress and stress drop within upper-bound period, $\mathrm{T}_{\text {upr }}$, as defined in the text. The left-handed-side diagrams belong to the $M_{L} 6.4$ aftershock and the right-handed-side ones belong to the $M_{L} 6.0$ aftershock.

decay with frequency (f) in a power-law relation, with an exponent of about -2 when $f>f_{c}$ ( $f_{c}=0.8 \mathrm{~Hz}$ for the $M_{L} 6.4$ event and $f_{c}=1.2 \mathrm{~Hz}$ for the $M_{L} 6.0$ one). Also included in Fig. 4 is the relationship of spectral amplitude and frequency (shown with dashed line) based on Brune's

Table 1. The estimated source parameters of the two larger aftershocks of the Chi-Chi earthquake.

\begin{tabular}{|c|c|c|c|c|c|c|}
\hline $\mathbf{M}_{\mathbf{L}}$ & $\begin{array}{c}\Delta \sigma_{s} \\
\text { (bars) }\end{array}$ & $\begin{array}{c}\sigma_{a} \\
\text { (bars) }\end{array}$ & $\frac{\sigma_{a}}{\Delta \sigma_{s}}$ & $\begin{array}{c}\mathbf{M}_{\mathbf{o}} \\
\text { (dyne-cm) }\end{array}$ & $\begin{array}{c}\mathbf{E}_{\mathbf{s}} \\
\text { (ergs) }\end{array}$ & $\mathbf{E}_{s} / \mathbf{M}_{\mathbf{0}}$ \\
\hline 6.4 & 991 & 402 & 0.4 & $1.2 \times 10^{25}$ & $1.6 \times 10^{22}$ & $1.3 \times 10^{-3}$ \\
\hline 6.0 & 831 & 337 & 0.4 & $4.6 \times 10^{24}$ & $4.8 \times 10^{2:}$ & $1.0 \times 10^{-3}$ \\
\hline
\end{tabular}

$\Delta \sigma_{s}:$ static stress drop ; $\sigma_{a}:$ apparent stress

$M_{o}$ : seismic moment : $E_{\mathrm{s}}$ : seismic-wave energy 

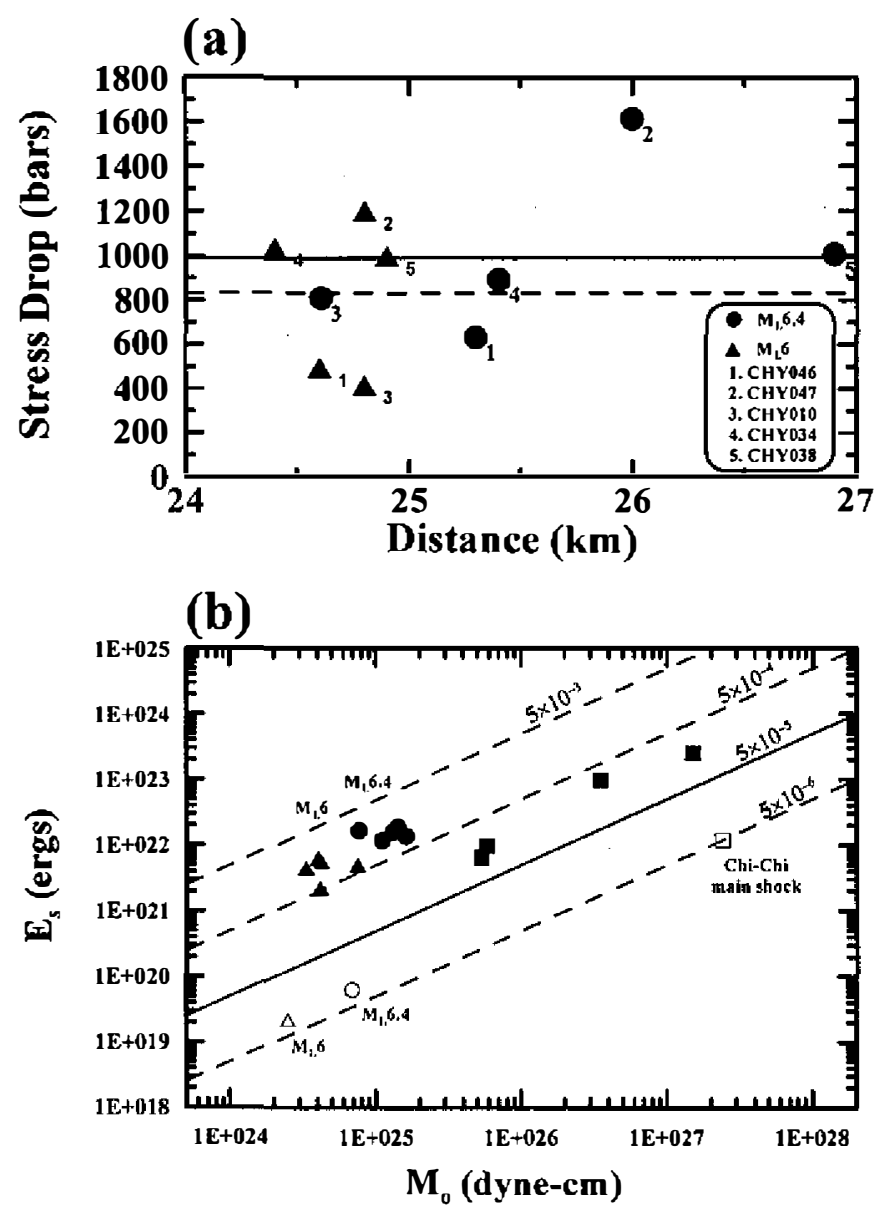

Fig. 7. (a) The distributions of stress drop with hypocentral distance: circles for the $M_{L} 6.4$ aftershock and triangles for the $M_{L} 6.0$ aftershock. (b) Logarithmic diagram of $E_{s}$ versus $M_{o}$ (solid symbols for the values estimated from local data and open symbols for those estimated from related data listed in the Harvard CMT earthquake catalogue; circles for the $M_{L} 6.4$ aftershock and triangles for the $\mathrm{M}_{\mathrm{L}} 6.0$ aftershock) and the relative values of the Chi-Chi mainshock obtained by Hwang et al. (2001): The solid squares for the values estimated from near-field data and the open square from the USGS catalogue. Lines associated with four values of $E_{s} M_{0}$, i. e., $5 \times 10^{-6}, 5 \times 10^{-5}, 5 \times 10^{-4}$, and $5 \times 10^{-3}$, as explained in the text.

source model. Although the observed spectral amplitude does not fit the theory perfectly, it still shows that the observed spectral amplitudes do follow Brune's source model. We estimated the $M_{0}$ value by applying the value of $\Omega_{0}$ with infinite time period instead of a period of 17.5 seconds. Of course, the estimated $M_{0}$ value could be less than $M_{0}$ value obtained from the long-period seismic waves recorded at remote stations since the amount of longer-period seis- 
mic waves are weak in local seismograms.

As shown in Fig. 5, the variations of cumulative energy for the two events at five stations varied from each other. This might be mainly due to three reasons: the first one is that the stations are situated at positions with different values of seismic radiation, the second one is the path effect, and the third is the site effect. Since the five stations are all close to the epicenters of these two events, they all situated in almost similar geological structures, thus eliminating the path effects. In the Taiwan region, Lee et al. (2001) stated large site effects exist mainly in the higher-frequency range. With similar pattern of the variations of cumulative values at all stations, we assumed the spatial variation in seismic-wave radiation caused by a focal mechanism must be the main reason to cause these observations. In addition, when $\mathrm{f}$ is larger than 6 $\mathrm{Hz}$, the cumulative value of the $M_{L} 6.4$ event is several times larger than that of the $M_{L} 6.0$ one, because the former is larger than the latter.

From Fig. 7a, it is obvious that the $\Delta \sigma$ value for the $M_{L} 6.4$ event is slightly dependent on the hypocentral distance, but not for the $M_{L} 6.0$ one. The estimated $\Delta \sigma$ values for the two events vary in a large range from 500 bars to 1600 bars. The reason to cause this large variation is the same as that mentioned previously for Fig. 5.

From Fig. 7b, we can see that the $\mathrm{E}_{\mathrm{s}} \mathrm{M}_{\mathrm{o}}$ values of the two aftershocks estimated from seismograms from five stations do not vary much between stations. The averaged $\mathrm{E}_{\mathrm{s}} \mathrm{M}_{\mathrm{o}}$ values estimated from near-field data are $1.3 \times 10^{-3}$ and $1.0 \times 10^{-3}$, for the $M_{L} 6.4$ and $M_{L} 6.0$ events (Table 1). It is obvious that the near-field $\mathrm{E}_{s} / \mathrm{M}_{0}$ values are about two orders larger in magnitude than the teleseismic one, this is the same conclusion obtained by other authors (Smith et al. 1991; Singh and Ordas 1994; Hwang et al. 2001) that the $E_{s} / M_{o}$ value estimated from near-field seismograms is usually larger than that from far-field ones. Based on near-field data, the values of $\mathrm{E}_{\mathrm{s}} / \mathrm{M}_{\mathrm{o}}$ for the Chi-Chi mainshock and the two aftershocks distribute around the line with $5 \times 10^{-4}$ (cf. Fig. 7b). The values of the two aftershocks are slightly larger than that of the mainshock. This might mean that the percentage of strained energy transferred to seismic-wave energy is slightly larger for the two aftershocks than for the mainshock. The values of $\mathrm{E}_{\mathrm{s}} / \mathrm{M}_{\mathrm{o}}$ estimated from teleseismic data also showed the same conclusion.

Ramón Zúñiga (1993) proposed a parameter of $\varepsilon$ denoted by $\varepsilon=\Delta \sigma /\left(\sigma_{\mathrm{a}}+0.5 \Delta \sigma\right)$ to be an indication to classify stress drop model: $\varepsilon>1$ for a frictional overshoot mechanism and $\varepsilon<1$ for a partial-stress-drop mechanism. According to Table $1, \sigma_{\mathrm{a}}$ and $\Delta \sigma / 2$ values of these two events both lead to $\varepsilon=1.104>1$ suggested rupture processes by frictional overshoot mechanism for these two events. For the Chi-Chi mainshock, Hwang et al. (2001) also obtained the same conclusion. Smith et al. (1991) and Ramón Zúñiga (1993) obtained different result and proposed. They described the displacement spectra beyond the corner frequency by a $\omega^{-1}$ decay function. For such spectra, the seismic-wave energy shows a $\omega^{-2}$ decay. In this study, the displacement spectra beyond the corner frequency show a $\omega^{-2}$ decay (Fig. 4). Hence, the seismic-wave energy estimated in this study, especially at high frequencies, is not as high as expected by Smith et al. (1991).

Based on the assumption that the dynamic stress level on the fault plane equals to the final one after an earthquake, Orowan (1960) stressed that the theoretical $\sigma_{a} / \Delta \sigma$ value is 0.5 . The estimated $\sigma_{a} / \Delta \sigma$ value in this study is about 0.4 , which is somewhat close to 0.5 , this might indicate the dynamic stress levels of these two aftershocks are close to the final one. The $\sigma_{\mathrm{a}}$ f 
$\Delta \sigma$ ratio of the Chi-Chi mainshock is 0.4 (Hwang et al. 2001), which is the same as ours, indicated of mechanically uniform conditions in the whole seismogenic zone.

\section{CONCLUSIONS}

The averaged source parameters of stress drop $(\Delta \sigma)$, apparent stress $\left(\sigma_{\mathrm{a}}\right)$, and scaled energy $\left(E_{s} / M_{o}\right)$ for the two large aftershocks $\left(M_{L}=6.4, M_{L}=6\right)$ of the Chi-Chi Earthquake are : $\Delta \sigma=991$ bars, $\sigma_{\mathrm{a}}=402$ bars, and $\mathrm{E}_{\mathrm{s}} / \mathrm{M}_{\mathrm{o}}=1.3 \times 10^{-3}$ for the $\mathrm{M}_{\mathrm{L}} 6.4$ event; and $\Delta \sigma=831$ bars, $\sigma_{\mathrm{a}}=331$ bars, and $\mathrm{E}_{\mathrm{s}} / \mathrm{M}_{\mathrm{o}}=1.0 \times 10^{-3}$ for the $\mathrm{M}_{\mathrm{L}} 6.0$ one. These results suggest high dynamic stress drop, which is also proportional to the magnitude of the aftershock. This suggested the larger aftershock ansformed a higher percentage of strain energy into the seismic-wave energy. Both local and teleseismic data yielded slightly larger $\mathrm{E}_{s} \mathrm{M}_{\mathrm{o}}$ values for the two aftershocks than the mainshock, and suggested frictional overshooting stress model as the rupturing processes based on Ramon Zuniga's parameter (1993). The dynamic stress levels of these two events are close to the final one according to Orown's assumption (1960).

Acknowledgements The authors would like to express deep thanks to the editor and two reviewers for their comments and the Central Weather Bureau for providing seismic data. This study was financially supported by Academia Sinica and the National Science Council, ROC (under Grant No. NSC91-2119-M-001-007).

\section{REFERENCES}

Aki, K., 1967: Scaling law of seismic spectrum. J. Geophys. Res., 72, 1217-1231.

Andrews, D. J., 1986: Objective determination of source parameters and similarity of earthquakes of different size, in Earthquake Source Mechanics. In: S. Das, J. Boatwright and C. H. Scholz (Eds.). Washington DC: Am. Geophys. Union, 259-267.

Bolt, B. A., 1986: Seismic Energy release over a broad frequency band. PAGEOPH, 124, 919-930.

Boore, D. M., and J. Boatwright, 1984: Average body-wave radiation coefficients. Bull. Seism. Soc. Am., 74, 1615-1621.

Brune, J. N., 1970: Tectonic stress and the spectra of seismic shear wave from earthquakes. $J$. Geophys. Res., 75, 4997-5009.

Choy, G. L., and J. L. Boatwright, 1995: Global patterns of radiated seismic energy and apparent stress. J. Geophys. Res., 100, 18205-18228.

Huang, B.-S., K.-C. Chen, W.-G. Huang, J.-H. Wang, T.-M. Chang, R.-D. Hwang, H.-C. Chiu, and C.-C. Tsai, 2000: Characteristics of strong ground motion across a thrust fault tip from the September 21, 1999, Chi-Chi, Taiwan, earthquake. Geophys. Res. Lett., 27, 2729-2733.

Huang, W. G., J. H. Wang, B. S. Huang, K. C. Chen, T. M. Chang, R. D. Hwang, H. C. Chiu, and C. C. Tsai, 2001: Estimates of source parameters for the Chi-Chi, Taiwan, earthquake, based on Brune's source model. Bull. Seism. Soc. Am., 91, 1190-1198.

Hwang, R. D., J. H. Wang, B. S. Huang, K. C. Chen, W. G. Huang, T. M. Chang, H. C. Chiu, 
and C. C. Tsai, 2001: Estimates of stress drop of the Chi-Chi, Taiwan, earthquake of 20 September 1999 from near-field seismograms. Bull. Seism. Soc. Am., 91, 1158-1166.

Kanamori, H., and T. H. Heaton, 2000: Microscopic and macroscopic physics of earthquakes, in GeoComplexity and the Physics of Earthquakes. Geophys. Monog. AGU, 120, 147163.

Kanamori, H., 1994: Mechanics of earthquakes. Annu. Rev. Earth Planet. Sci., 22, 207-237.

Kao, H., and J. Angelier, 2001: Stress transfer for the Chi-Chi earthquake sequence and its implications on regional collision. Bull. Seism. Soc. Am., 91, 1028-1040.

Kikuchi, M., and Y. Fukao, 1988: Seismic wave energy inferred from long-period body wave inversion. Bull. Seism. Soc. Am., 78, 1707-1724.

Lee C.-T., C. T. Cheng, C. W. Liao, and Y.-B. Tsai, 2001: Site classification of Taiwan freefield strong-motion stations. Bull. Seism. Soc. Am., 91, 1283-1297.

Liu, K.-S., T.-C. Shin, and Y.-B. Tsai, 1999: A free-field strong motion network in Taiwan: TSMIP. TAO, 10, 337-396.

Ma, K.-F., C.-T. Lee, Y.-B. Tsai, T.-C. Shin and J. Mori, 1999: The Chi-Chi, Taiwan earthquake: Large surface displacements on an inland thrust fault. Eos, Transaction, American Geophysical Union, 80, 605-611.

Orowan, E., 1960: Mechanism of seismic faulting. Geol. Soc. Am. Mem, 79, 323-345.

Ramón Zúñiga, F., 1993: Frictional overshoot and partial stress drop: which one? Bull. Seism. Soc. Am., 83, 939-944.

Rau, R. J., F. T. Wu, and T. C. Shin, 1996: Regional network focal mechanism determination using 3D velocity model and SH/P amplitude ratio. Bull. Seism. Soc. Am., 86, 12701283.

Shin, T. C., K. W. Kuo, W. H. K. Lee, T. L. Teng, and Y. B. Tsai, 2000: A preliminary report on the 1999 Chi-Chi (Taiwan) earthquake. Seism. Res. Lett., 71, 24-30.

Singh, S. K., and M. Ordaz, 1994: Seismic energy release in Mexican subduction zone earthquakes. Bull. Seism. Soc. Am., 84, 1533-1550.

Smith, K. D., J. N. Brune, and K. F. Priestley, 1991: The seismic spectrum, radiated energy, and Savage and Wood inequality for complex earthquakes. Tectonophys., 188, 303320.

Vassiliou, M. S., and H. Kanamori, 1982: The energy release in earthquakes. Bull. Seism. Soc. Am., 72, 371-387.

Wang, J. H., R. D. Hwang, K. C. Chen, B. S. Huang, C. H. Chiu, C. C. Tsai, W. G. Huang, and T. M. Chang, 2000: The M 7.6 Chi-Chi, Taiwan, earthquake of September 20, 1999, Proceed. Int. Workshop on Seismotectonics in the Subduction Zone, Tsububa, Japan, 351-360.

Wyss, M., and J. N. Brune, 1968: Seismic moment, stress, and source dimensions for earthquakes in the Califorina-Nevada regions. J. Geophsy. Res.,73, 4681-4694. 